\title{
Collection Center Location with Equity Considerations in Reverse Logistics Networks
}

\author{
Iş1 Tari ${ }^{a, b}$, Sibel A. Alumur ${ }^{c}$ \\ isil.basmaci@gmail.com, sibel.alumur@uwaterloo.ca \\ ${ }^{a}$ Department of Mechanical and Industrial Engineering, Ryerson University, Toronto, Ontario, \\ Canada \\ ${ }^{b}$ Department of Industrial Engineering, TOBB University of Economics and Technology, Söğütözü, \\ Ankara, Turkey \\ ${ }^{c}$ Department of Management Sciences, University of Waterloo, Waterloo, Ontario, Canada
}

\begin{abstract}
In this paper, we study a collection center location problem with equity considerations within reverse logistics network design. The aim of the problem is to determine the locations and the capacities of the collection centers through the planning horizon. For each time period, the decisions to be made include the location and the capacities of the collection centers, the amounts of products to send from each generation point to each collection center, and the amounts of products to send from each collection center to each firm. The problem has three objectives. The first one is to minimize total cost, the second one is to ensure equity among different firms, and the third is to provide steady flow of products to each firm along the planning horizon. The problem is modeled as a multi-objective mixed integer programming formulation. An implementation of the problem in Turkey within the context of waste electrical and electronic equipment collection is presented. Sensitivity analyses are conducted to observe the effect of changes in the problem parameters on the solutions. The analyses include changes in the fixed costs and container capacities, changes in the amount of supply and changes in the growth rate. In addition, the solution potential of the model and value of using a multi-period model as opposed to using a static one are investigated.
\end{abstract}

Keywords: Facility Location, Equity, Multi-objective Model, WEEE.

\section{Introduction}

Collection centers are established for collecting and storing end-of-use and end-of-life products for proper recovery. These centers act as drop-off stations for generation points. In many countries, legislations enforce separate collection of various product categories and set recovery targets for original equipment manufacturers. Even though extended producer responsibilities present in many legislations give the responsibility of recovering used products to original equipment manufacturers, governments need to establish the necessary infrastructure. For example, in Denmark, Germany, and Romania the responsibility of building the necessary infrastructure for collecting Waste Electrical and Electronic Equipment (WEEE) has been given solely to municipalities. In some other countries within the European Union 
(for example Austria, Belgium, France, Portugal, and the Netherlands), responsibilities are shared among distributors, producers, and the municipalities.

The end-of-life or end-of-use products which are no longer needed because of various reasons are generated at generation points (private households, commercial, industrial and institutional sources). According to legislations present in various countries, such as the European Union WEEE Directive (2002), all of the generated end-of-use products must be collected. To collect these products, there is a need for the establishment of collection centers. In order to facilitate collection, these collection centers should be located at convenient places which are relatively easy to reach from these generation points.

Products that are collected at collection centers are then sent to distributors, original equipment manufacturers or some other parties, which we will refer as 'firms', for proper recovery, including options such as reusing, refurbishing, remanufacturing, and/or recycling. Each firm needs to collect and recover a certain amount of used products set by the legislations, usually dependent on the firm's market share and referred as the recovery target. Besides satisfying recovery targets, many firms gain profit from the return of these used products, for example, by reusing some valuable components or by selling some of the valuable materials (Krikke et al. 1999, Dowlatshahi 2000). Thus, in addition to fulfilling legislative requirements, many firms are willing to collect as much of these returned products as possible. However, authorities must ensure equitable distribution of the excess amount of products to different firms who are willing to collect different types of products. In various countries, unfortunately, this planning is not done in advance, which usually results in an unfair distribution of products among different firms. For example, in United Kingdom, some firms over collected and sold their WEEE surplus to under-quota firms. It was then decided by the High Court that this action breaks UK regulations and the electronics manufacturers should not systematically collect more electronic waste than they have produced (England and Wales High Court 2009).

In addition to equitable distribution of flow among different firms, in order to plan remanufacturing activities for each type of product, each firm would prefer a steady flow of used products from the collection centers. To ensure this, a multi-period planning approach needs to be considered. Additionally, as emphasized by Melo et al. (2006), a multi-period approach allows the possibility of making future adjustments in the network configuration.

The contributions of this paper are threefold: First, is to provide a mathematical model to solve the collection center location problem considering equity objectives. Second, is to illustrate a realistic application of this model within the context of WEEE collection. Finally, is to present an empirical study for the effect of changes in the problem parameters on the resulting solutions and for the value of the multi-period planning.

The overview of this paper is as follows. The next section reviews the relevant literature. 
Section 3 presents the problem definition. In Section 4, we present a multi-objective mixedinteger linear programming formulation of the problem. Section 5 presents an application of the problem with data from Turkey. This section also includes our multi-objective solution strategy. Section 6 presents sensitivity of the effect of changes in the problem parameters on the resulting solutions. The paper concludes with some final remarks and future research directions presented in Section 7.

\section{Literature Review}

There are various studies in the literature on collection center location in reverse logistics or closed-loop supply chain networks. Our focus will be on the studies that consider multiple types of products while locating collection centers within reverse logistics networks. We do not aim to provide an exhaustive review of the literature. The reader can refer to Fleischmann et al. (1997), Fleischmann et al. (2004), Akçalı et al. (2009), Pokharel and Mutha (2009), Aras et al. (2010), and Govindan et al. (2015) for reviews on this area.

One of the earlier studies considering facility location problems in reverse logistics networks is Barros et al. (1998). In this study, a two-level location model is proposed for recycling multiple types of used sand in the Netherlands. The proposed model decides on the locations of the regional depots and treatment facilities while minimizing total costs. Similarly, Jayaraman et al. (2003) minimize total costs to find the optimal locations of collection centers and refurbishing facilities for multiple types of products. They allow direct shipments from customer sites to refurbishing facilities and introduce a heuristic solution methodology.

Schultmann et al. (2003) study reverse logistics network design within the context of the collection and processing of used batteries in Germany. Multiple types of used batteries with different chemical compositions are collected while determining the locations of the batterysorting facilities and minimizing total costs.

Min et al. (2006) propose a nonlinear mixed integer programming model for determining the locations of centralized return centers. The objective function minimizes total costs and it is non-linear due to the modeling of the consolidation of returns over time. The authors propose a genetic algorithm to solve this two-level reverse logistics network design problem. Bautista and Pereira (2006) model the problem of locating collection areas using a set covering

type formulation. A genetic algorithm and a GRASP heuristic is proposed and applied using data on the municipal waste collection in Barcelona.

Pati et al. (2008) present a mixed integer goal programming model for a paper recycling system. The objectives considered are minimization of reverse logistics cost, maximizing product quality, and maximizing environmental benefits through increased wastepaper recovery. 
The proposed model aims to determine the locations of the facilities and the flows of different types of recyclable wastepaper.

In addition to determining the optimal locations of collection centers, some studies also optimize the financial incentive to be offered in order to stimulate collection of used products. Figueiredo and Mayerle (2008) determine the optimal number and locations of receiving centers when there is a required throughput for recycling. They present a conceptual framework, an analytical model, and a solution algorithm for determining the optimal financial incentive to be offered in addition to finding the optimal locations of the receiving facilities. Similarly, Aras and Aksen (2008), Aras et al. (2008), and Aksen et al. (2009) determine the optimal incentive values to be offered while deciding on the optimal locations of collection centers so as to maximize a company's profit from the returns. Aras and Aksen (2008) consider a drop-off strategy, whereas Aras et al. (2008) assume that a pick-up strategy is in place. Aksen et al. (2009), on the other hand, present bi-level programming models describing the subsidization agreement between the government and a company engaged in collection and recovery operations.

All of the above mentioned studies consider only the reverse part of the network, that is, they do not include the forward flows. There are also some studies focusing on designing closed-loop networks while deciding on the optimal locations of different types of facilities. We do not aim to integrate forward and reverse logistics networks in this study. The reader can refer to Krikke et al. (2003), Fleischmann et al. (2004), Üster et al. (2007), Easwaran and Üster (2009), Pishvaee et al. (2010), and Salema et al. (2010) for exemplary studies on determining the locations of facilities within closed-loop supply chain networks.

There are also some papers dealing with uncertainty while locating facilities in reverse logistics networks. Various sources of uncertainty are considered such as uncertainty in the supply and demand, uncertainty in the transportation costs, and uncertainty in the revenues. Examples of studies considering uncertainty while determining the locations of facilities within reverse or closed-loop logistics networks are Realff et al. (2004), Liştes and Dekker (2005), Salema et al. (2007), Lee and Dong (2009), Fonseca et al. (2010), Qin and Ji (2010), and De Rosa et al. (2013). We do not model uncertainty in this paper; however, we present extensive sensitivity and scenario analysis to observe the effects of various problem parameters on the resulting solutions.

In this paper, we consider a multi-period setting and allow the locations and the capacities of the collection centers, and the flows through the network to change over time. There are some studies in the literature also modeling the dynamic nature of the problem. For example, Realff et al. (2004) develop a robust mixed-integer linear programming model that maximizes profit for recycling multiple types of carpets in a multi-period setting. Flows in the network 
changes over time in the proposed model; however, the facility location and capacity decisions remain static. Srivastava (2008) proposes a conceptual model for collection center location in a three-echelon reverse logistics network to maximize profits allowing discrete capacity expansions for the facilities. Lee and Dong (2009) propose a cost minimizing multi-period model for determining the locations of processing facilities and collection centers, and the flows in the reverse logistics network over time. Capacity expansion is not allowed for the facilities. A two-stage stochastic programming model is further developed to account for the uncertainties in both demand and supply.

Ko and Evans (2007) propose a dynamic model for the design of a closed-loop network integrating forward and reverse logistics. They allow capacity expansion for the collection and distribution facilities, which are to be located, over time. The proposed cost minimizing model is non-linear and it is solved by a genetic algorithm based heuristic. Salema et al. (2010) also study a multi-period multi-product closed-loop network design problem. They minimize total costs while determining the network structure, storage levels, amounts of flow, and the amounts of non-satisfied demand and return volumes while considering macro and micro time periods. Gomes et al. (2011) present an implementation of the model presented in Salema et al. (2010) considering only the reverse part of the network for locating sorting facilities within a case study for the recovery of WEEE in Portugal.

A more recent study by Alumur et al. (2012) consider the design of reverse logistics networks in a multi-period setting as well. The proposed model designs a reverse logistics network for an original equipment manufacturer by determining the locations of inspection centers and remanufacturing plants so as to maximize the firm's profits. Kim and Lee (2013) minimize total cost to locate collection centers while allowing dynamic allocation of demand points to collection centers over a given planning horizon with discrete time periods. Toso and Alem (2014) developed both a deterministic and a stochastic capacitated facility location model considering discrete time intervals for locating sorting facilities in Brazil.

None of the studies referred above considers the equity perspective in collection center location problem. Equity objectives are widely used in public sector location problems. One may refer to Marsh and Schilling (1994) for a review on equity measurement in facility location analysis. Some recent studies on facility location problems considering equity are AlçadaAlmeida et al. (2009), Berman et al. (2009), Drezner and Drezner (2011). Lejeune and Prasad (2013), and Batta et al. (2014). Different measures of equity are proposed in these studies; nevertheless, equity for sending flows to different firms within a reverse logistics network is not considered.

Marsh and Schilling (1994) present various equity measures that can be used within the context of facility location. We use two of these measures. Firstly, we use minimizing the 
maximum range measure in order to send equitable amounts of excess flow among different firms. Secondly, we minimize the maximum deviation from the mean demand values to ensure steady flow of products to each firm during the planning horizon. Detailed definition of our problem is provided in the next section.

\section{Problem Definition}

In this paper, we solve a collection center location problem for municipalities. This location problem results in the design of a two-echelon multi commodity reverse logistics network. End-of-use products that are generated at various generation points are brought to collection centers which are to be located. Used products are sorted and stored at these collection centers. Products are then sent to different firms for proper recovery. Firms need to collect end-of-use products to achieve their recovery targets set by the legislations. This network structure is depicted in Figure 1.

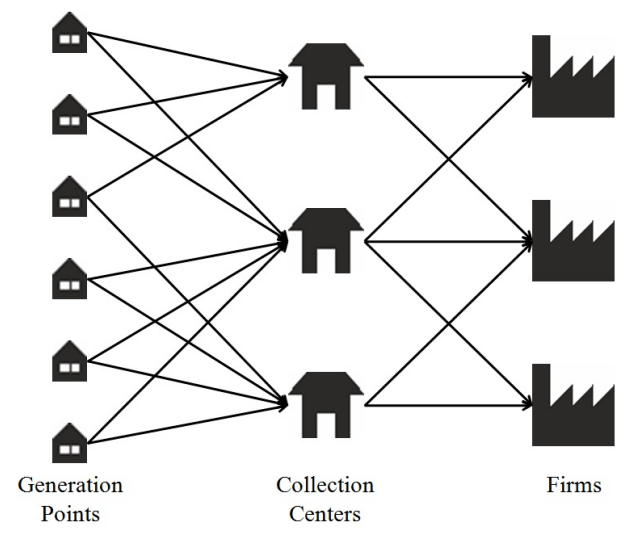

Figure 1: 2-echelon reverse logistics network.

In order to facilitate the collection of products, collection centers must be located close to the generation points. Depending on the application, municipalities can be responsible for collecting products from the generation points or users can drop-off their used products to collection centers by themselves. In this study, we assume that there are transportation costs in transporting used products from generation points to collection centers and from collection centers to different firms.

Different types of products are collected and stored in collection centers. There are dedicated containers to store each product category. These containers can be of various sizes and capacities depending on the product category. Containers can be gradually added to the collection centers during the planning horizon. It is assumed that there is enough space in collection centers to handle containers and that there is no limit on the amount of containers that can be bought by the municipalities. 
There are costs involved in establishing this reverse logistics network. Municipalities' first objective is to minimize total cost which includes the costs of establishing and operating collection centers, costs of buying containers for different types of products, inventory holding costs at the collection centers, and transportation costs of products. It is assumed that all cost values are scaled considering the duration of the planning horizon.

The demand of each firm for each product type is usually determined by the legislations depending on the firm's market share; for example, on the total amount of products placed on the market in the preceding year by the firm. In this study, it is assumed that the demand of each firm for each product type is known and that there is enough supply to cover the demand of all the firms. It is possible for the firms to collect more than the amount that they demand. As explained in the introduction, firms gain profit from these used products. Thus, firms are willing to collect as much of these used products as possible. However, municipalities must ensure equitable distribution of the excess amount of products to firms. In order to ensure this, an equity objective is introduced into the problem minimizing the maximum difference in the excess amounts of products that are sent to different firms by the municipalities. The sizes of the firms are not taken into account; however, it is possible to take proportions into consideration.

In addition to ensuring equity among different firms, municipalities would like to assure steady flow of used products from the collection centers to each firm during the planning horizon. Most of the firms prefer a steady flow in order to properly plan their remanufacturing activities. For each firm, a steady flow can be attained by minimizing the maximum deviation from the firm's mean demand through the planning horizon, which is the third objective of the problem.

The collection center location problem addressed in this paper for the municipalities determines the locations and the capacities of the collection centers, the amounts of products to send from each generation point to each collection center, and the amounts of products to send from each collection center to each firm. The problem has three objectives. The first one is to minimize total cost, the second one is to ensure equity among different firms, and

the third is to provide steady flow of products to each firm along the planning horizon. The next section introduces a mathematical programming formulation for this problem.

\section{Multi-objective Mixed Integer Programming Model}

In this section, we introduce a multi-objective linear mixed integer programming model for collection center location problem with equity considerations in reverse logistics networks faced by the municipalities.

We consider a multi-period setting where the planning horizon is assumed to be finite 
and divided into several time periods. All the network design decisions are taken over this planning horizon and implemented in the beginning or end of the time periods. For each time period, the decisions to be made include the location and the capacities of the collection centers, amounts of products to send from each generation point to each collection center and the amounts of products to send from each collection center to each firm. We assume that once a collection center is opened, it remains open until the end of the planning horizon.

The parameters and the decision variables of the mathematical model are listed as below.

\section{Parameters}

$P$

$T \quad$ Set of periods in the planning horizon.

$G \quad$ Set of generation points.

$C \quad$ Set of potential collection center locations.

$K_{p} \quad$ Set of container types that can be used in collection centers for product $p \in P$.

$C_{\text {Cap }} \quad$ Capacity of container type $k \in K_{p}$ that can be used for product $p \in P$.

$F_{p} \quad$ Set of firms that collect product $p \in P$.

$S_{i p}^{t} \quad$ Supply of product $p \in P$ from generation point $i \in G$ in period $t \in T$.

$D_{f p} \quad$ Demand of firm $f \in F_{p}$ for product $p \in P$ for the whole planning horizon.

\section{Costs}

$T C_{i j p}^{t} \quad$ Unit transportation cost of product $p \in P$ sent from generation point $i \in G$ to collection center $j \in C$ in period $t \in T$.

$T C_{j f p}^{t} \quad$ Unit transportation cost of product $p \in P$ sent from collection center $j \in C$ to firm $f \in F_{p}$ in period $t \in T$.

$F C_{j}^{t} \quad$ Fixed cost of establishing and operating a collection center at location $j \in C$ from the beginning of period $t \in T$ until the end of the planning horizon.

$K C_{k p}^{t} \quad$ Cost of buying a container of type $k \in K_{p}$ to be used for product $p \in P$ in period $t \in T$ until the end of the planning horizon.

$I C_{j p}^{t} \quad$ Unit inventory holding cost at collection center $j \in C$ for product $p \in P$ in period $t \in T$.

\section{Decision variables}

$x_{i j p}^{t}=$ Amount of product $p \in P$ sent from generation point $i \in G$ to collection center $j \in C$ in period $t \in T$.

$w_{j f p}^{t}=$ Amount of product $p \in P$ sent from collection center $j \in C$ to firm $f \in F_{p}$ in period $t \in T$.

$I_{j p}^{t}=$ Amount of product $p \in P$ held in inventory in collection center $j \in C$ in the end of period $t \in T$. 
$e_{f p}=$ Excess amount of product $p \in P$ sent to firm $f \in F_{p}$.

$y_{j}^{t}= \begin{cases}1 & \text { If collection center } j \in C \text { is operating in period } t \in T, \\ 0 & \text { otherwise. }\end{cases}$

$z_{j k p}^{t}= \begin{cases}1 & \text { If a container of type } k \in K_{p} \text { is bought for collection center } j \in C \text { to be used for } \\ & \text { product } p \in P \text { in the beginning of period } t \in T \\ 0 & \text { otherwise. }\end{cases}$

\section{Mixed integer programming formulation}

With the parameters and the decision variables introduced above, the collection center location problem in reverse logistics networks can be formulated as follows:

$$
\begin{aligned}
& \text { Min } \sum_{t \in T} \sum_{i \in G} \sum_{j \in C} \sum_{p \in P} T C_{i j p}^{t} x_{i j p}^{t}+\sum_{t \in T} \sum_{j \in C} \sum_{f \in F_{p}} \sum_{p \in P} T C_{j f p}^{t} w_{j f p}^{t}+\sum_{t \in T} \sum_{j \in C} \sum_{p \in P} I C_{j p}^{t} I_{j p}^{t} \\
& +\sum_{t \in T} \sum_{j \in C} F C_{j}^{t}\left(y_{j}^{t}-y_{j}^{t-1}\right)+\sum_{t \in T} \sum_{j \in C} \sum_{k \in K_{p}} \sum_{p \in P} K C_{k p}^{t} z_{j k p}^{t} \\
& \text { Min } \operatorname{Max}_{p \in P, f, \bar{f} \in F_{p}: f \neq \bar{f}}\left|e_{f p}-e_{\bar{f} p}\right| \\
& \operatorname{Min} \operatorname{Max}_{p \in P, f \in F_{p}, t \in T}\left|\sum_{j \in C} w_{j f p}^{t}-\frac{D_{f p}}{|T|}\right| \\
& \text { s.t. } \quad S_{i p}^{t}=\sum_{j \in C} x_{i j p}^{t} \quad i \in G, p \in P, t \in T \\
& \sum_{i \in G} x_{i j p}^{t}+I_{j p}^{t-1}=\sum_{f \in F_{p}} w_{j f p}^{t}+I_{j p}^{t} \quad j \in C, p \in P, t \in T \\
& \sum_{t \in T} \sum_{j \in C} w_{j f p}^{t}=D_{f p}+e_{f p} \quad f \in F_{p}, p \in P \\
& \sum_{i \in G} x_{i j p}^{t}+I_{j p}^{t} \leq \sum_{k \in K_{p}} \sum_{\tau=1}^{t} C a p_{k p} z_{j k p}^{\tau} \quad j \in C, p \in P, t \in T \\
& \sum_{k \in K_{p}} z_{j k p}^{t} \leq y_{j}^{t} \quad j \in C, p \in P, t \in T \\
& y_{j}^{t-1} \leq y_{j}^{t} \quad j \in C, t \in T \\
& y_{j}^{0}=0 \quad j \in C \\
& I_{j p}^{0}=0 \quad j \in C, p \in P \\
& x_{i j p}^{t}, w_{j f p}^{t}, I_{j p}^{t}, e_{f p} \geq 0, \quad i \in G, j \in C, p \in P, f \in F_{p}, t \in T \\
& y_{j}^{t} \in\{0,1\}, \quad j \in C, t \in T \\
& z_{j k p}^{t} \in\{0,1\}, \quad j \in C, k \in K_{p}, p \in P, t \in T
\end{aligned}
$$


The problem is a multi-objective problem with three objective functions (1)-(3). The first objective function (1) minimizes total cost. The total cost is composed of transportation costs of products from generation points to collection centers and from collection centers to firms, inventory holding cost at collection centers, fixed cost of establishing collection centers, and cost of buying containers. The second objective function (2) ensures equity among different firms. By this objective function, the maximum difference between the excess amount of products that are sent to different firms is minimized. The third objective function (3) ensures steady flow of products to each firm throughout the planning horizon. For each period, firm, and product, the maximum deviation from the mean demand is minimized via this third objective function.

Constraints (4)-(6) are flow balance constraints at generation points, collection centers, and firms, respectively. Constraint (4) ensures that all of the products that are supplied from the generation points are sent to collection centers. Constraint (5) is the flow balance constraint at collection centers guaranteeing that the total amount of inflow is equal to the total amount of outflow at collection centers. For each period, the inflow at collection centers consists of the amount of products that are sent from generation points and the amount of products held in the inventory at the end of the previous period. The outflow consists of the total amount of products that are sent to different firms and the amount of products to be held in inventory. Constraint (6) ensures that each firm receives its demand for each product from the collection centers. It is possible for the firms to receive more than the amount they demanded which is referred as the 'excess amount'.

Constraint (7) is the capacity constraint for the collection centers. For each period and product, the amount of products received and the amount held in inventory cannot exceed the capacity of the containers that are bought for this product until that period.

By constraint (8), containers can be bought only for established collection centers and at most one type of container can be bought in each period for each product. Constraint (9) assures that once a collection center is established, it remains open until the end of the planning horizon.

We assume that no collection center is already established and hence no inventory is held in the beginning of the planning horizon. These are ensured with constraints (10) and (11). However, these constraints can be modified accordingly if there are collection centers which are already operating in an existing reverse logistics network.

Lastly, constraints (12) are the non-negativity constraints and constraints (13) and (14) are binary restrictions.

The model introduced above is non-linear due to absolute value functions that are present 
in the objective functions (2) and (3). The absolute value functions can easily be linearized by using the mathematical relation $|x|=\operatorname{Max}\{x,-x\}$.

In order to linearize objective function (2), we define a new decision variable Equity I $_{1}$ and let

$$
\text { Equity }_{1}=\operatorname{Max}_{p \in P, f, \bar{f} \in F_{p}: f \neq \bar{f}}\left\{e_{f p}-e_{\bar{f} p},-e_{f p}+e_{\bar{f} p}\right\}
$$

Then, objective function (2) can be linearized by introducing the below constraints to the model.

$$
\begin{array}{ll}
\text { Min } & \text { Equity }_{1} \\
\text { s.t. } & \text { Equity }_{1} \geq e_{f p}-e_{\bar{f} p} \quad p \in P, f, \bar{f} \in F_{p}: f \neq \bar{f} \\
& \text { Equity }_{1} \geq-e_{f p}+e_{\bar{f} p} \quad p \in P, f, \bar{f} \in F_{p}: f \neq \bar{f}
\end{array}
$$

Similarly, to linearize objective function (3), we define a new decision variable Equity 2 and let

$$
\text { Equity }_{2}=\operatorname{Max}_{p \in P, f \in F_{p}, t \in T}\left\{\sum_{j \in C} w_{j f p}^{t}-\frac{D_{f p}}{|T|},-\sum_{j \in C} w_{j f p}^{t}+\frac{D_{f p}}{|T|}\right\}
$$

The objective function (3) can then be linearized by introducing the below constraints to the model.

$$
\begin{array}{ll}
\text { Min } & \text { Equity }_{2} \\
\text { s.t. } & \text { Equity }_{2} \geq \sum_{j \in C} w_{j f p}^{t}-\frac{D_{f p}}{|T|} \quad p \in P, f \in F_{p}, t \in T \\
& \text { Equity }_{2} \geq-\sum_{j \in C} w_{j f p}^{t}+\frac{D_{f p}}{|T|} \quad p \in P, f \in F_{p}, t \in T
\end{array}
$$

The multi-objective linear mixed integer programming formulation of the problem is with objective functions (1), (15), and (18) and constraints (4)-(14), (16), (17), (19), and (20).

\section{Application in Turkey}

The model is applied with data from Turkey. In Turkey, determining the locations of the collection centers is the responsibility of the greater municipalities. We applied our model considering the data from the greater municipality of Ankara within the context of collection of Waste Electrical and Electronic Equipment (WEEE). The greater municipality of Ankara covers an area of $24,938 \mathrm{~km}^{2}$ with a population of 4,890,893 (Turkish Statistical Institute 2011). WEEE Directive has recently become law in Turkey (Turkish Ministry of Environment WEEE Directive 2012) and the infrastructure for collecting WEEE has not been set yet. 
In our application, 39 points ( 25 municipalities and 14 districts) are identified as generation points within the greater municipality of Ankara. These points also represent potential collection center locations (Data 2014). In order to determine the amount of WEEE generated at each generation point, it is assumed that $9.6 \mathrm{~kg} /$ person of WEEE is generated per year (Sayman et al. 2012). This value is multiplied by the population of the municipalities and districts to determine the total amount of WEEE generated at 39 generation points at the end of a 1-year planning horizon. We additionally performed some sensitivity analysis to observe the effects of changes in the amount of supply which is detailed in Section 6.2.

The planning horizon is taken as one year consisting of six two-month periods. The yearly growth rate of WEEE is used in order the determine the amount of supply in the beginning of each two-month period. The yearly growth rate of WEEE is taken as $2 \%(0.33 \%$ for two months) (Sayman et al. 2012). In Section 6, we analyze the changes in the solutions with different lengths of the planing horizon and with alternative growth scenarios.

WEEE are collected in four different categories. Each category represents a different product type in our model. The largest category is large household appliances accounting for $48 \%$ of the total amount of WEEE generated, the second largest category is IT and telecommunications equipment and consumer equipment with a total share of $27 \%$. The third category contains small household appliances, electrical and electronic tools, toys, leisure and sports equipment, medical devices, and monitoring and control instruments with a total of $18 \%$ share. The last and the smallest category of products is lighting equipment accounting for $7 \%$ of the total amount of WEEE that is generated.

Different firms need to collect these different product categories from the collection centers to achieve their recovery targets set by the WEEE Directive. It is assumed that there are 5 hypothetical firms (A, B, C, D, and E) that are responsible for collecting products. Each product category is assumed to be collected by three distinct firms.

In Turkey, similar to the applications in some other European countries such as Germany, the firms are responsible for collecting their own demand from the collection centers. Each firm is notified by the greater municipality about the amounts of products that they are going to collect from each collection center during the planning horizon. Since each firm is responsible for its own collection, the costs beared by the municipality of transporting products from collection centers to firms are taken to be independent from the location of the firms.

Distances between generation points and potential collection centers are obtained using the transportation network. Unit transportation costs of products sent from generation points to collection centers are taken as $0.005 \mathrm{EUR} / \mathrm{km}-\mathrm{kg}$ for each type of product (Alumur et al. 2012). Unit transportation costs of products from collection centers to firms, on the other 
hand, are taken as $0.05 \mathrm{EUR} / \mathrm{kg}$. In Section 6.4, we present an analysis with the results when the transportation costs from collection centers to firms are dependent on each firm's location.

Fixed annual cost of establishing and operating a collection center is taken as 400,000 EUR (Alumur et al. 2012). In Ankara, land prices are generally higher in populated municipalities. A parameter is used to reflect these differences in fixed costs. For each potential collection center location, this parameter is calculated by adding one to the ratio of the municipality or district's population to the total population.

For each product category, three different types of containers with three different capacities (large, medium, and small) can be bought. The purchasing costs of these containers are estimated based on market research.

All the cost parameters increase by the annual average inflation rate of $3 \%$ during the planning horizon which is the rounded-up value of the annual average inflation rate of European Union reported by the European Statistics Institute (2012). The inflation rate is gradually applied in each period.

In order for the results to be reproducible, the values of all the problem parameters for this application are presented in Data (2014).

All the runs are done on a computer with a $2.6 \mathrm{GHz}$ Intel Core Duo processor and $8 \mathrm{~GB}$ of RAM and using OPL CPLEX 12.4.

\subsection{Multi-objective solution method}

The mathematical formulation introduced in Section 4 is a multi-objective model with three objective functions. The first objective function is the minimization of total cost, the second is to ensure equity among different firms (Equity $)_{1}$, and the third is to ensure steady flow of products to each firm (Equity $)$.

In Turkey, the decisions on the locations of collection centers are to be given solely by the municipalities. In our application, the decision maker is the greater municipality of Ankara. Considering all the objectives, evidently, minimization of total cost has the highest priority for the municipality. Thus, it was decided to take equity objectives into consideration only to discriminate among the solutions that minimize the total cost.

When the remaining two equity objectives are taken into account, since ensuring equity among different firms is considered to have a higher priority than ensuring a steady flow to each firm, it is decided that the third objective is to be considered only for the solutions which optimize initially the first and then the second objective. Thus, for the solution of this multiobjective problem the "lexicographic method" is adopted. That is, the problem is initially solved only with the first objective function (1) (Model-1). Then, the optimum cost value is 
included in the model as an upper bound on the total cost and the model is solved considering only the second objective function (15) (Model - 2). Finally, the last objective function (18) is optimized with upper bound constraints on total cost and Equity $($ Model - 3).

Model - 1

$$
\begin{aligned}
\text { TotalCost }^{*}= & \text { Min } \\
\text { s.t. } & (1)-(14)
\end{aligned}
$$

Model - 2

$$
\begin{aligned}
\text { Equity }_{1}^{*}=\text { Min } & \text { (15) } \\
\text { s.t. } & \text { (4) }-(14),(16),(17) \\
& \sum_{t \in T} \sum_{i \in G} \sum_{j \in C} \sum_{p \in P} T C_{i j p}^{t} x_{i j p}^{t}+\sum_{t \in T} \sum_{j \in C} \sum_{f \in F_{p}} \sum_{p \in P} T C_{j f p}^{t} w_{j f p}^{t} \\
& +\sum_{t \in T} \sum_{j \in C} \sum_{p \in P} I C_{j p}^{t} I_{j p}^{t}+\sum_{t \in T} \sum_{j \in C} F C_{j}^{t}\left(y_{j}^{t}-y_{j}^{t-1}\right) \\
& +\sum_{t \in T} \sum_{j \in C} \sum_{k \in K_{p}} \sum_{p \in P} K C_{k p}^{t} z_{j k p}^{t} \leq \text { TotalCost }
\end{aligned}
$$

Model - 3

$$
\begin{aligned}
\text { Equity }_{2}^{*}=\text { Min } & (18) \\
\text { s.t. } & (4)-(14),(16),(17),(19)-(21) \\
& \text { Equity }_{1} \leq \text { Equity }_{1}^{*}
\end{aligned}
$$

While solving Model -2 and Model - 3, in order to reduce the solution times in CPLEX, we have fixed the optimal locations of the established collection centers from the output of Model -1 .

We would like to point out that, since unit transportation costs from collection centers to firms are the same for all firms and independent from the firms' location (as explained in the beginning of Section 5 each firm is responsible for collecting its own demand from the collection centers), the location of the collection centers does not have an impact on both of the equity measures, only the flow and inventory decisions does. In particular, Equity objective is in fact not conflicting with the total cost objective in this application. As a result, in this application, total cost and Equity ${ }_{1}$ objectives can achieve their minimum values at the same time. However, this does not mean that there is no need to optimize Equity . Note

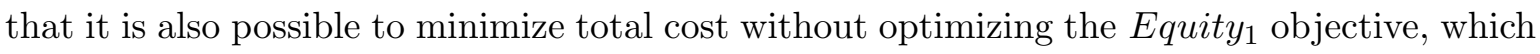
would result in an unfair distribution of products among firms. In Section 6.4, we analyze 
the trade-off between the three objective function values when the transportation costs from collection centers to firms are dependent on each firm's location.

We have taken all the runs to optimality and from now on (in this section and the next one) we only report the optimal solutions as a result of Model-3. CPU times that we report, on the other hand, is the sum of the CPU times as a result of solving Model - 1, Model - 2, and Model -3 , consecutively. That is, the CPU times that are reported are the accumulated CPU times.

\subsection{Results of the base case}

In this section, we analyze the results of the problem with the parameter values described in the beginning of Section 5. We refer to this instance of the problem as the 'base case'. The base case resulted in a model with 3,081 binary variables, 40,659 continuous variables, 4,853 constraints, and it is solved by CPLEX in 32 seconds using the methodology described in the previous section.

Figure 2 shows the optimal locations of the collection centers and the allocations of the generation points to these collection centers considering the flow of all product categories. Figure 2(a) shows the allocations at the end of the first period and Figure 2(b) at the end of the last period.

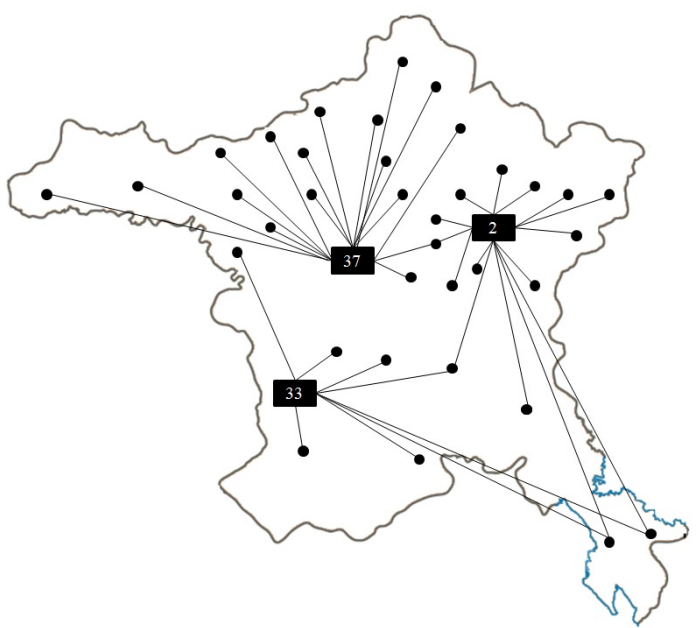

(a) End of the first period.

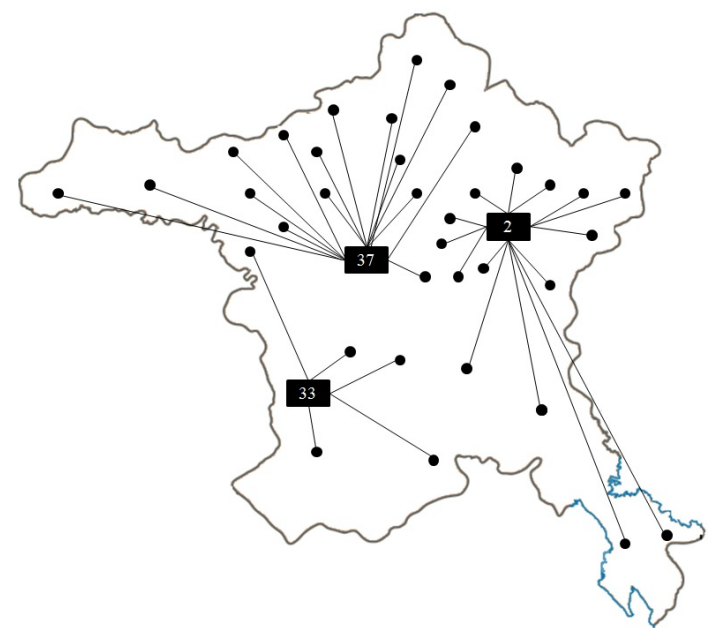

(b) End of the last period.

Figure 2: Base case solution.

In this base case solution, collection centers are established at Altındağ (2), Polatlı (33), and Sincan (37) municipalities all in the beginning of the planning horizon. Containers for different types of products are bought in the first two periods. Note that in Figure 2(a) some generation points send their flows to two different collections centers at the end of the first 
period. This is because there are not enough containers at the collection centers at the end of the first period. When more containers are bought and the capacities of the collection centers are increased through the planning horizon, we observe from Figure 2(b) that all generation points are allocated to a single collection center at the end of the planning horizon.

More generation points are allocated to the collection centers located at Altındağ (2) and Sincan (37) compared to Polatlı (33). This is because Altındağ and Sincan are more centrally located and thus they are relatively closer to the generation points than Polatli. Figure 3 shows the total amount of flow sent to the located collection centers through the whole planning horizon. At the end of the last period, $74.47 \%$ of the total amount of all the generated products are sent to the collection center located at Altındağ, 21.97\% to Sincan, and $3.56 \%$ to Polatlı (Figure 3). In order to handle more inflow, more containers are bought for the collection centers located at Altındağ and Sincan compared to Polatli.

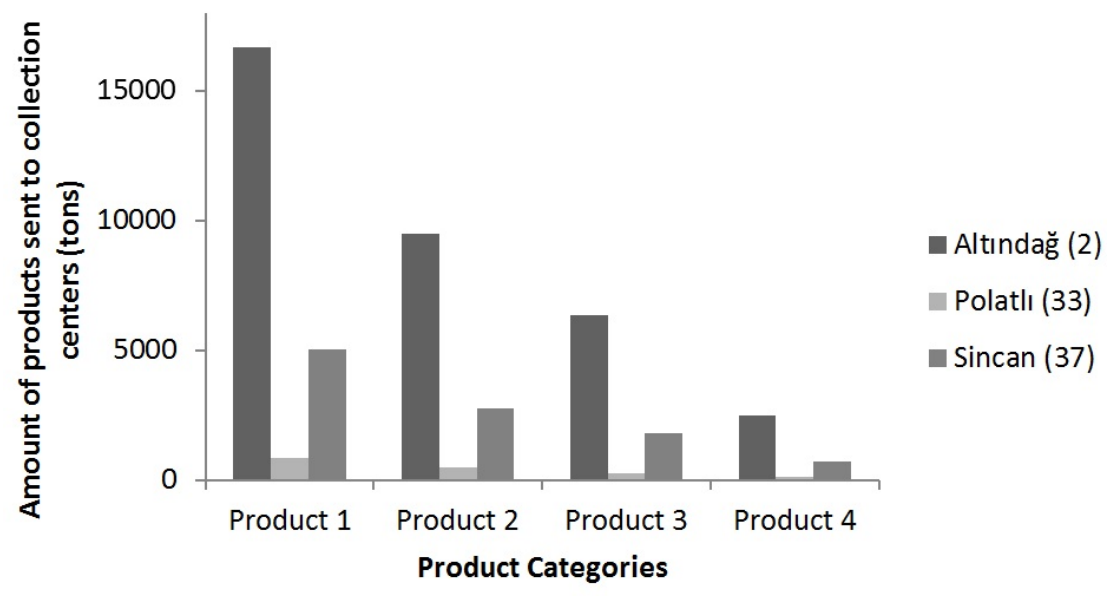

Figure 3: Total amount of flow sent to collection centers.

No inventory was held in any of the collection centers throughout the planning horizon. This is because the primary objective of the model is the minimization of total cost and the other objectives (Equity 1 and Equity $_{2}$ ) are considered among the solutions that minimize total cost.

The second objective function aims to ensure equity among different firms by minimizing the maximum difference between the excess amounts of products that are sent to different firms. As explained in Section 4, it is possible to send firms more than the amount they demand, which is referred as the excess amount. The optimum value of the second objective function $\left(E_{\text {Equity }}\right)$ is zero for this base case solution. That is, none of the firms received more excess amount of product than the other for each product category and thus, equity is ensured among the firms. Figure 4 depicts the total excess amount of products sent to firms $\mathrm{A}, \mathrm{B}, \mathrm{C}, \mathrm{D}$, and E through the planning horizon. 


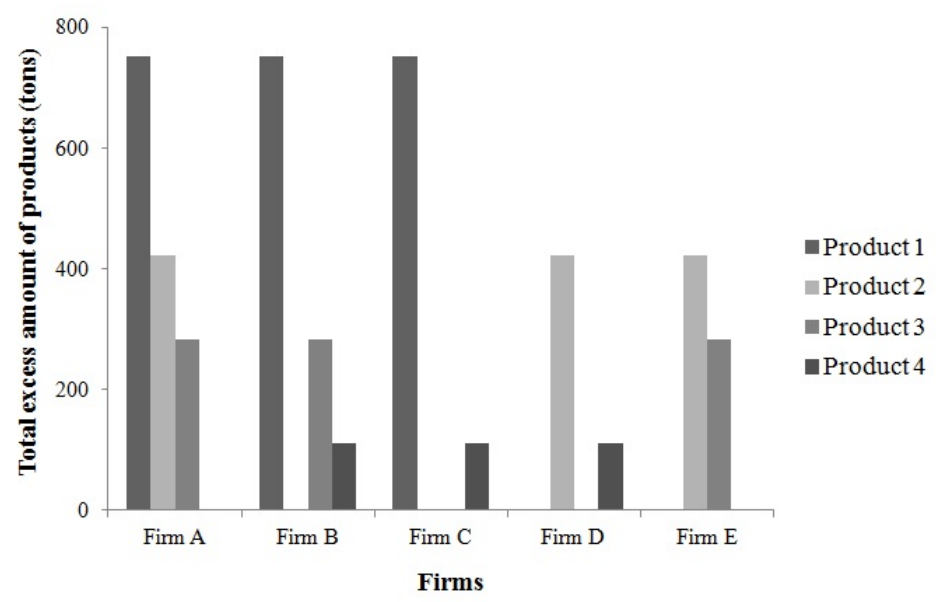

Figure 4: Total excess amount of products sent to different firms.

As can be observed from Figure 4, each firm receives exactly the same excess amount

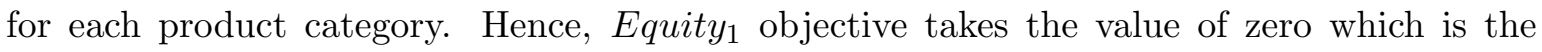
ideal value that this objective function can get. As noted in the previous section, Equity objective is not conflicting with the total cost objective in this application; hence, both of these objectives can achieve their minimum values at the same time.

The third objective function (Equity $)$ ensures that the firms receive steady flow of products through the planning horizon by minimizing the maximum deviation from the mean demand. The value of the Equity 2 objective is $135,542 \mathrm{~kg}$ for this base case solution. Figure 5 depicts the total amount of products sent to firms A and B through the planning horizon.

In Figure 5, firms A and B are taken as examples and for each one, the mean demand for each product category is shown with horizontal lines. The maximum deviation from the mean demand for all product categories among all the firms is $135,542 \mathrm{~kg}$ which is the value

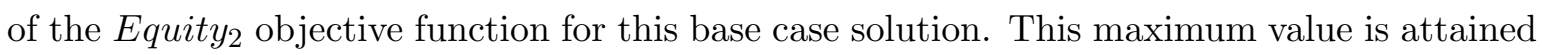
for different firms and for different product categories concurrently. For example, for Firm A, the maximum deviation from the mean demand value is achieved at periods 2,4 , and 6 for product category 1, and at periods 3 and 6 for product category 2. Similarly, for Firm B, the maximum deviation from the mean demand value is attained at periods $2,3,5$, and 6 for product category 1 , periods 4,5 , and 6 for product category 3 , and periods 1,2 , and 4 for product category 4 . The graphs for the amount of products sent to the remaining three firms are very similar.

The results of the base case solution revealed that most of the generation points, hence, majority of the flow, are allocated to centrally located collection centers. Moreover, all generation points are allocated to a single collection center at the end of the planning horizon. 


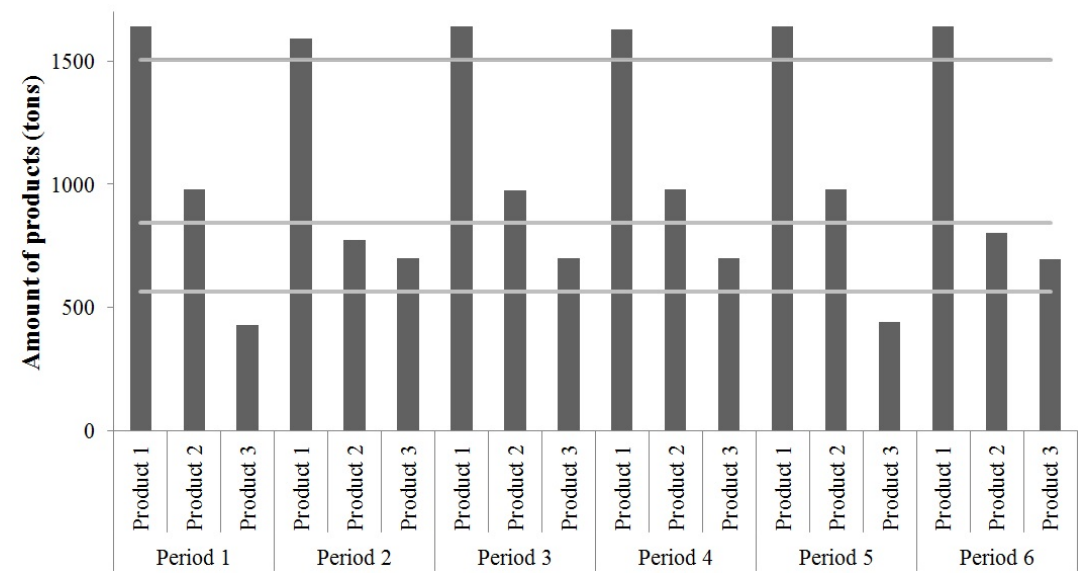

(a) Firm A

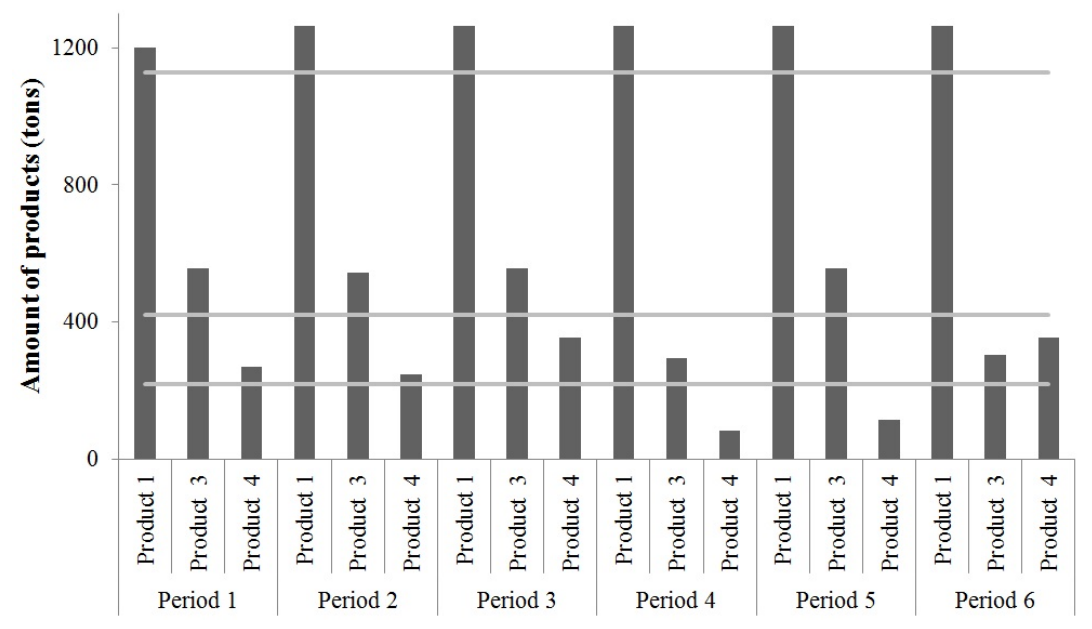

(b) Firm B

Figure 5: The amount of products sent to Firms A and B through the planning horizon.

Since the primary objective is the minimization of total cost, no inventory is held at the

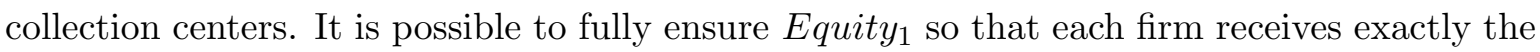
same excess amount of product within each product category.

\section{Sensitivity Analysis}

We extended the computational analysis with the parameter settings presented in the previous section to observe the effects of changes in various problem parameters on the solutions.

\subsection{Changes in the fixed costs and container capacities}

Initially, we analyze the changes in the solutions with different annual fixed cost values for establishing and operating collection centers and also with different container capacities. We varied fixed cost values between 100,000 and 1,000,000 EUR. In addition to the set of container 
capacities introduced in the previous section, we generated two new capacity sets: tight and loose. The medium capacity set corresponds to the container capacities that are used in the base case solution. The results with varying fixed costs and capacities are presented in Table 1.

The first column in Table 1 lists the instance numbers. We analyze a total of 30 different instances. The second column presents which capacity set is used in the corresponding instances. For each instance, the third column lists the value of the fixed cost for establishing and operating collection centers. Columns four to six report the resulting objective

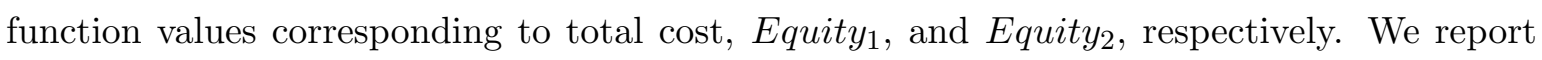
the optimal collection center locations in the seventh column. In the last column, we present the total CPU time requirements to solve the multi-objective model by adopting the lexicographic method detailed in Section 5.1. The base case explained in Section 5.2 corresponds to instance number 14 .

As expected, more collection centers are established with lower fixed cost values. For example, 11 or 12 collection centers are located when the fixed cost values are set to 100,000 EUR (instances 1, 11, and 21) whereas only two or three collection centers are used with higher fixed cost values. In addition to fixed costs, capacities of the containers also effect the total number of collection centers to be established. For a given fixed cost value, more collection centers are located with tight capacity values (Set 3) compared with the other capacity sets. In particular, with the highest fixed cost value, two collection centers are established in instances 10 and 20, whereas three collection centers are located at the last instance with the tightest capacity set.

A collection center is established at Sincan (37) in all the instances. Additionally, Altındağ (2), Polatlı (33), Çankaya (11), and Keçiören (24) are among the most preferred locations. These municipalities are more centrally located and also more populated. Due to higher population, higher amounts of products are generated in these municipalities compared with the other candidate locations.

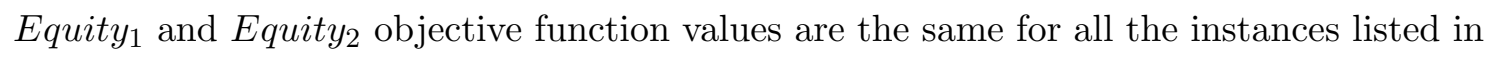
Table 1. These equity results have already been explained in more detail in Section 5.2 on the base case solution (instance 14). In all the instances in Table 1, no inventory is held at the collection centers because the primary objective is the minimization of total cost. With no inventory being held, we do not expect a change in the equity objectives with different fixed cost values or container capacities. Thus, it is normal to have the same equity values for all the instances in Table 1. In particular, as explained in the previous section, since total cost and Equity 1 objectives are not conflicting objectives with the current cost data, there is

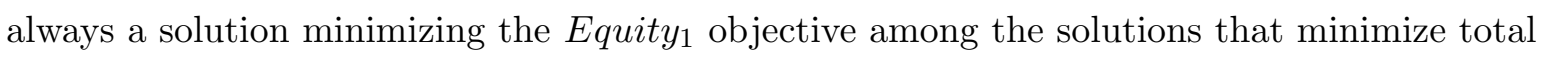




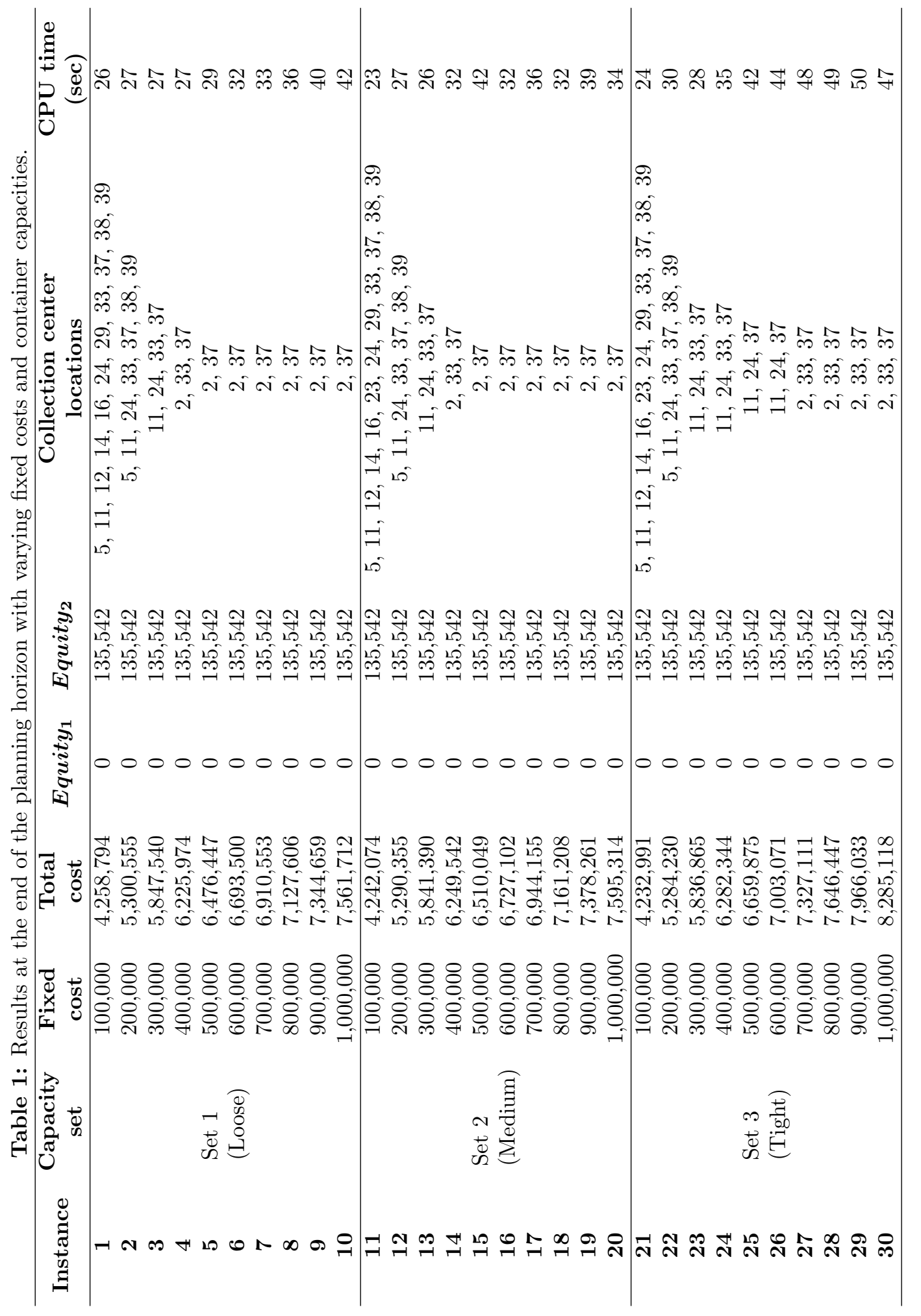


cost.

The last column of Table 1 lists the CPU time requirement to solve each instance. The problem is solved in reasonable CPU times in all the instances. Instances with lower fixed cost values tend to be solved quicker. The minimum CPU time requirement by CPLEX is 23 seconds, whereas the maximum is 50 seconds.

\subsection{Changes in the amount of supply}

In Section 5, it is assumed that $9.6 \mathrm{~kg} /$ person of WEEE is generated per year (Sayman et al. 2012). According to UNU (2008), this amount varies between 6-12 kg/person-year for new members of the European Union. In this section, we assume that the amount of products generated at each generation point is uniformly distributed between 6 and $12 \mathrm{~kg} /$ person per year. We generated ten different instances to observe the effects of changes in the amount of supply on the solutions. For this analysis, the fixed cost value is taken as 400,000 EUR and the medium capacity set is used as in the base case. Results of ten different instances are presented in Table 2.

Table 2: Solutions at the end of the planning horizon with different amounts of supply.

\begin{tabular}{ccccccc}
\hline Instance & $\begin{array}{c}\text { Total } \\
\text { supply }\end{array}$ & $\begin{array}{c}\text { Total } \\
\text { cost }\end{array}$ & Equity $_{\mathbf{1}}$ & Equity $_{\mathbf{2}}$ & $\begin{array}{c}\text { Collection center } \\
\text { locations }\end{array}$ & $\begin{array}{c}\text { CPU time } \\
\text { (sec) }\end{array}$ \\
\hline Base case & $46,952,573$ & $6,249,542$ & 0 & 135,542 & $2,33,37$ & 32 \\
$\mathbf{3 1}$ & $49,472,206$ & $6,369,136$ & 0 & 133,304 & $11,24,33,37$ & 37 \\
$\mathbf{3 2}$ & $47,531,107$ & $6,176,132$ & 0 & 137,213 & $2,11,33,37$ & 35 \\
$\mathbf{3 3}$ & $45,749,005$ & $5,974,084$ & 0 & 132,068 & 2,37 & 45 \\
$\mathbf{3 4}$ & $42,785,889$ & $5,815,025$ & 0 & 123,514 & $2,33,37$ & 33 \\
$\mathbf{3 5}$ & $40,554,856$ & $5,599,775$ & 0 & 117,074 & $2,33,37$ & 37 \\
$\mathbf{3 6}$ & $52,631,161$ & $6,607,954$ & 0 & 151,936 & $11,24,33,37$ & 31 \\
$\mathbf{3 7}$ & $51,249,186$ & $6,502,815$ & 0 & 147,902 & $11,24,33,37$ & 39 \\
$\mathbf{3}$ & $50,846,710$ & $6,518,259$ & 0 & 146,750 & $11,24,33,37$ & 41 \\
$\mathbf{3 9}$ & $49,721,440$ & $6,318,408$ & 0 & 143,535 & $11,24,37$ & 37 \\
$\mathbf{4 0}$ & $41,568,949$ & $5,645,630$ & 0 & 120,001 & 2,37 & 38 \\
\hline
\end{tabular}

For each instance, Table 2 lists the amount of total supply, the values of the three objective functions, the locations of the collection centers, and the CPU time requirements. The first row of Table 2 corresponds to the base case solution presented in Section 5.2.

Total cost values are close to each other in the instances in Table 2. Note that the Equity objective function takes the value of zero in all the instances. This shows that no matter what the value of the amounts of generated products are, there is always a solution where each firm can get the same excess amount of products from the collection centers.

$E_{\text {quity }}$ objective function values, on the other hand, change with the variation in the amount of supply. However, again the values are relatively close to each other.

When we look at the optimal collection center locations, we observe that the most preferred 
locations are Polatl (33) and Sincan (37). Additionally, in some instances collection centers are located at Altındağ (2), Çankaya (11), and Keçiören (24) municipalities. Changes in the amount of supply do not effect the locations of the collection centers drastically. More collection centers are located in the instances where relatively higher amounts of products are generated. On the other hand, two or three collection centers are established in the instances where the amount of supply is relatively low. Note that total cost is not directly proportional to the amount of total supply. This is because at each of the instances each generation point generates a different amount which results in the differences in transportation costs.

Among the solutions listed in Table 2, the highest CPU time requirement is 45 seconds corresponding to instance 33. In all the instances, the problem is solved in average in about 36.8 seconds.

\subsection{Changes in the growth rate}

Next, we analyze the changes in the solutions with changes in the growth rate of the collected products during the planning horizon. As stated in the beginning of Section 5, the yearly growth rate of WEEE is taken as $2 \%$ (Sayman et al. 2012). In this section, we generated four different scenarios (two optimistic and two pessimistic) in addition to the constant increase of $2 \%$ in the base case. In the two optimistic scenarios that we generated (Optimist-1 and Optimist-2), the growth rate increases exponentially, and in the two pessimistic scenarios (Pessimist-1 and Pessimist-2), the growth rate decreases exponentially. Figure 6 demonstrates these growth rate scenarios on the total amount of category 1 product generated at Akyurt (1).

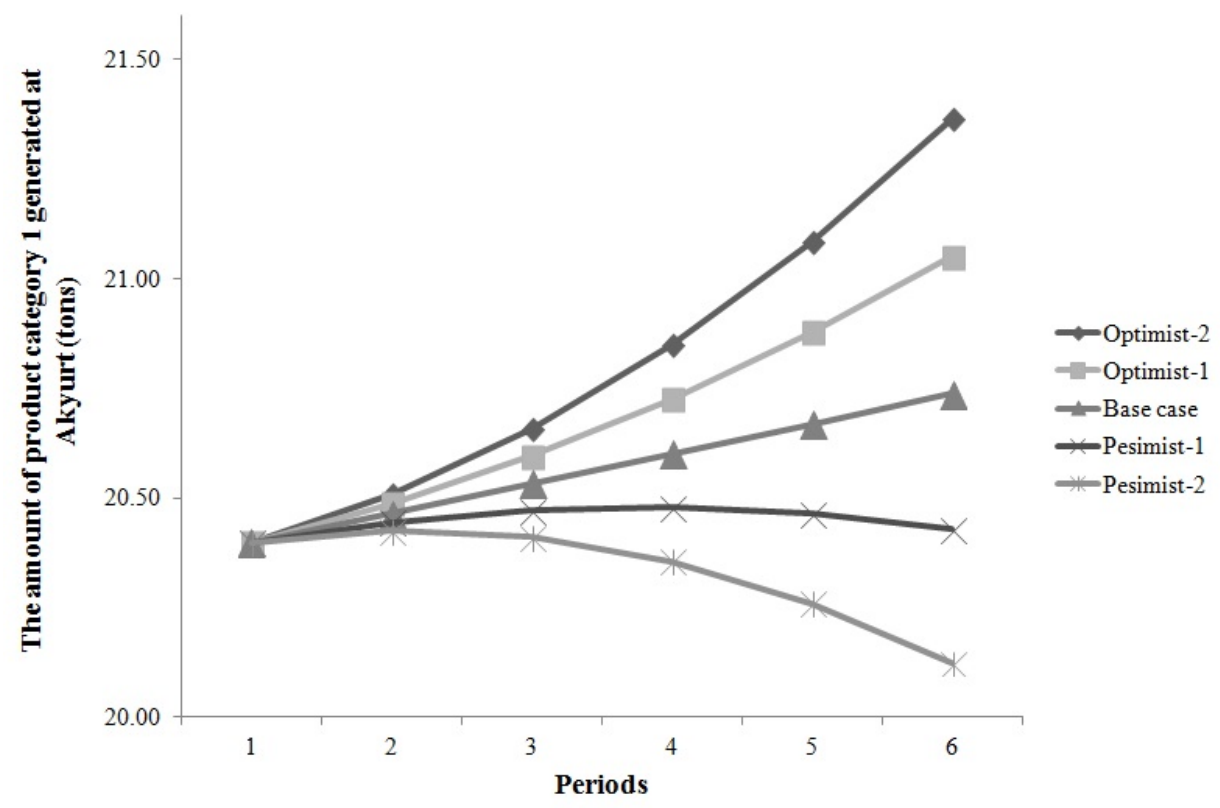

Figure 6: Alternative growth scenarios. 
All of the four different growth rate scenarios are tested with three different capacity sets for containers (loose, medium, and tight) and with an annual fixed cost of 400,000 EUR for establishing and operating a collection center. The results are summarized in Table 3.

Table 3: Solutions at the end of the planning horizon with different growth rate scenarios.

\begin{tabular}{llccccc}
\hline $\begin{array}{c}\text { Capacity } \\
\text { set }\end{array}$ & Scenarios & $\begin{array}{c}\text { Total } \\
\text { cost }\end{array}$ & Equity $_{\mathbf{1}}$ & Equity $_{\mathbf{2}}$ & $\begin{array}{c}\text { Collection center } \\
\text { locations }\end{array}$ & $\begin{array}{c}\text { CPU time } \\
\text { (sec) }\end{array}$ \\
\hline \multirow{4}{*}{ Set 1} & Optimist-2 & $6,284,498$ & 0 & 160,449 & $2,33,37$ & 35 \\
(Loose) & Optimist-1 & $6,255,125$ & 0 & 147,913 & $2,33,37$ & 37 \\
& Base case & $6,225,974$ & 0 & 135,542 & $2,33,37$ & 27 \\
& Pessimist-1 & $6,197,043$ & 0 & 126,324 & $2,33,37$ & 33 \\
& Pessimist-2 & $6,168,324$ & 0 & 129,601 & $2,33,37$ & 34 \\
\hline \multirow{5}{*}{ Set 2} & Optimist-2 & $6,308,066$ & 0 & 160,449 & $2,33,37$ & 42 \\
(Medium & Optimist-1 & $6,278,693$ & 0 & 147,913 & $2,33,37$ & 41 \\
& Base case & $6,249,542$ & 0 & 135,542 & $2,33,37$ & 32 \\
& Pessimist-1 & $6,220,610$ & 0 & 126,324 & $2,33,37$ & 35 \\
& Pessimist-2 & $6,191,892$ & 0 & 129,601 & $2,33,37$ & 42 \\
Set 3 & Optimist-2 & $6,335,797$ & 0 & 160,449 & $11,24,33,37$ & 42 \\
(Tight) & Optimist-1 & $6,308,948$ & 0 & 147,913 & $11,24,33,37$ & 40 \\
& Base case & $6,282,344$ & 0 & 135,542 & $11,24,33,37$ & 35 \\
& Pessimist-1 & $6,255,994$ & 0 & 126,324 & $11,24,33,37$ & 37 \\
& Pessimist-2 & $6,229,838$ & 0 & 129,601 & $11,24,33,37$ & 43 \\
\hline
\end{tabular}

Note that the locations of the collection centers are the same as in the base case solution (a constant increase of $2 \%$ ) under the four different growth rate scenarios for each capacity set in Table 3. In our application, the locations of the collection centers are not affected by the changes in the growth rate of the collected products at all. So, we may say that collection center locations are robust to changes in the growth rate.

Even though locations are the same, there can be differences in the capacity decisions. For example, an extra container is bought for the collection center located in Çankaya (11) in the Optimist-2 growth rate scenario with the tight capacity set in the second period.

When we look at the total costs, we can observe from Table 3 that total cost is higher in optimistic scenarios and lower in pessimistic scenarios compared with the total cost of the base case. Due to the increase in the amount of collected products, in addition to the increase in costs as a result of capacity acquisition, there is an increase in the transportation costs. More products being collected in optimistic scenarios results in higher transportation costs and less products being collected in pessimistic scenarios results in lower transportation costs.

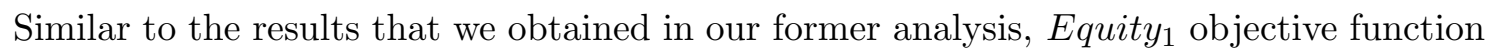
takes the value of zero in all the scenarios. This shows that even with different growth rate scenarios, it is possible to send the same excess amount of products to different firms through the planning horizon. Equity E $_{2}$ objective function, on the other hand, changes with varying growth rate. Note that with higher increase in the amount of products generated 
in the two optimistic scenarios, Equity2 objective function value gets higher. That is, it is more difficult to send a steady flow of products to firms through the planning horizon when there is an exponential increase in the growth rate of the products. On the other hand, note

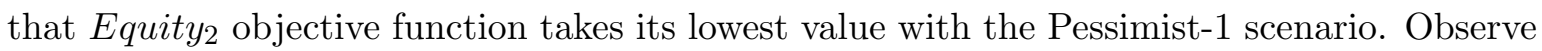
from Figure 6 that the minimum variation in the amount of products generated through the planning horizon is attained with the Pessimist- 1 scenario which resulted in sending a relatively steady flow of products to the firms.

Observe from Table 3 that the problem is solved again in reasonable times under all of the different growth rate scenarios with an average CPU time requirement of 37 seconds.

\subsection{Trade-off between the objectives}

As explained in the beginning of Section 5, each firm is responsible for its own collection and, thus, unit transportation costs of products from collection centers to firms are taken to be independent from the location of the firms. In this section, we consider otherwise and assume that the products are transported from the collection centers to firms by the municipalities.

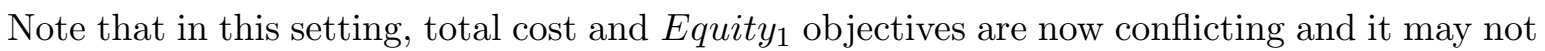
be possible for both of these objectives to achieve their minimum values at the same time.

Since there is no real data on the location of the firms, the distances between the potential collection center locations and the firms are obtained by generating a random value from the uniform distribution between 10 and $20 \mathrm{~km}$. The unit transportation costs of products sent from collection centers to firms are taken as $0.005 \mathrm{EUR} / \mathrm{km}-\mathrm{kg}$ for each type of product, which is equivalent to the unit transportation costs between generation points and collection centers.

We tested different objective function values as an upper bound in the lexicographic method, in order to observe the trade-off between the three objectives. The results are provided in Table 4.

In all the instances listed in Table 4, collection centers are established at the same locations. The total cost value of $6,739,988$ is the minimum cost value that can be attained under the parameter setting with the base case values (except the values of the transportation costs). Instance 41 corresponds to the minimum Equity 1 value that can be achieved with the minimum total cost. Note that it is not possible to fully achieve equity among the firms, if the minimum cost solution is to be adopted. Instance 42, on the other hand, corresponds to

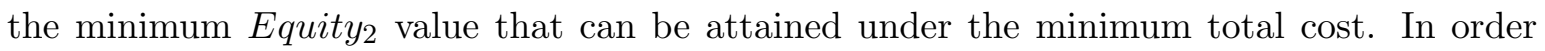
to obtain this solution, we changed the order of objectives in the lexicographic method: first minimized cost, followed by minimizing Equity 2 , and last by minimizing Equity .

In the instances numbered 43-52 in Table 4, we tested different upper bound values for 
Table 4: Trade-off between the objective function values.

\begin{tabular}{ccccc}
\hline Instance & $\begin{array}{c}\text { Total } \\
\text { cost }\end{array}$ & Equity $_{\mathbf{1}}$ & Equity $_{\mathbf{2}}$ & $\begin{array}{c}\text { Collection center } \\
\text { locations }\end{array}$ \\
\hline $\mathbf{4 1}$ & $6,739,988$ & $1,365,533$ & $1,687,150$ & $2,33,37$ \\
$\mathbf{4 2}$ & $6,739,988$ & $1,366,379$ & $1,517,104$ & $2,33,37$ \\
$\mathbf{4 3}$ & $6,800,000$ & 0 & 131,721 & $2,33,37$ \\
$\mathbf{4 4}$ & $6,800,000$ & 632,463 & 131,222 & $2,33,37$ \\
$\mathbf{4 5}$ & $7,000,000$ & 0 & 126,631 & $2,33,37$ \\
$\mathbf{4 6}$ & $7,000,000$ & 637,078 & 126,494 & $2,33,37$ \\
$\mathbf{4 7}$ & $7,500,000$ & 0 & 121,116 & $2,33,37$ \\
$\mathbf{4 8}$ & $7,500,000$ & 624,485 & 121,035 & $2,33,37$ \\
$\mathbf{4 9}$ & $8,000,000$ & 0 & 117,673 & $2,33,37$ \\
$\mathbf{5 0}$ & $8,000,000$ & 623,966 & 117,619 & $2,33,37$ \\
$\mathbf{5 1}$ & $8,500,000$ & 0 & 114,929 & $2,33,37$ \\
$\mathbf{5 2}$ & $8,500,000$ & 631,102 & 114,887 & $2,33,37$ \\
$\mathbf{5 3}$ & $57,817,642$ & 0 & 0 & $2,33,37$ \\
\hline
\end{tabular}

the total cost and minimized the two equity objectives interchangeably.

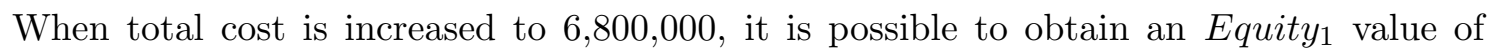
zero (instance 43). This shows that with a relatively little increase in costs, the municipality will be able to ensure equity among different firms. Instance 44 corresponds to the minimum Equity2 value that can be achieved when the upper bound on the total cost is $6,800,000$. Note from Table 4 that in order to achieve a steadier flow of products to firms with lower $E_{\text {Euity }}$ values, the decision maker has to bear inequitable flow of excess amount of products

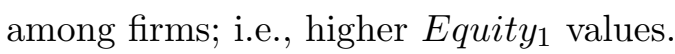

The last row of Table 4 corresponds to the solution when both of the equity objectives achieve their minimum values. If the municipality wants to assure equity among the firms as well as to send a steady flow of products to all the firms through the planning horizon, the total cost of the solution goes up to $57,817,642$. This is an extreme solution obtained under the circumstances when the total cost is not a concern for the decision maker at all.

Table 4 empirically demonstrates the trade-off between the objectives. The results show

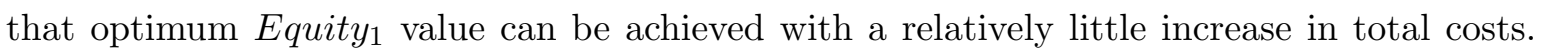
On the other hand, it may not be cost-effective to minimize Equity $y_{2}$. A small improvement in the Equity E objective may result in a steep decline in Equity . One may conclude considering the results obtained in Table 4 that the best approach would be to consider Equity 2 objective in the end.

\subsection{Advantage of multi-period planning}

The third objective function of the model, which is to ensure steady flow of products to each firm along the planning horizon, can only be considered within a multi-period setting. If the decision maker does not want to take this objective into account, then the problem does not 
need to be solved in a multi-period setting. In this case, the decision maker may prefer to solve a simpler problem consisting only of a single-period disregarding the time dimension and the inventory costs. However, using a multi-period approach can still be advantageous in terms of total cost compared to solving a static problem. In this section, we would like to analyze if it is advantageous in terms of total cost to use the multi-period approach that we are proposing, instead of solving a static problem with the available data. A similar analysis is introduced in Alumur et al. (2012).

In order to assess the advantage of using a multi-period approach, a static single-period problem is solved. This single-period problem is solved by taking into consideration only the maximum amount of products that are generated and the maximum values of costs through the planning horizon. Then, the results from this single-period solution has been fixed for the whole planning horizon. The total cost obtained by solving the multi-period problem is compared with the total cost obtained when the single-period solution is fixed through the whole planning horizon. Results with varying fixed costs and container capacities are presented in Table 5 .

For each fixed cost value and capacity set, Table 5 reports the resulting total cost and collection center locations, initially, when the single-period solution is fixed for 6 periods, and subsequently, when the problem is solved in a multi-period setting with 6 periods. The last column presents the percent difference in the resulting total costs.

Observe from Table 5 that the multi-period approach can be more advantageous up to $33 \%$ (about 1.4 million EUR) in terms of total cost compared to using a static approach. In this specific instance, 12 collection centers are operated in the multi-period solution, whereas, only two collection centers are operated in the single-period solution. If the solution with two collection centers is adopted for the whole planning horizon, then the total costs would be $33 \%$ higher than operating 12 collection centers. In other words, the cost of establishing ten extra collection centers is less than that of the decrease in transportation costs.

The percent difference hence the value of the multi-period solution is higher at the instances corresponding to lower fixed cost values. This is because with lower fixed costs, it is more advantageous to establish more collection centers when the decision maker plans in a multi-period setting to reduce the transportation costs of the whole planning horizon. On the other hand, a static approach considers the transportation costs of only a single period, and hence results in establishing relatively fewer collection centers and a higher total cost for the whole planning horizon.

With higher fixed cost values, the advantage of using the multi-period approach gets relatively lower. However, the optimum locations of the collection centers can be quite different. For example, in the last row of Table 5, even though there is a total cost difference of only 


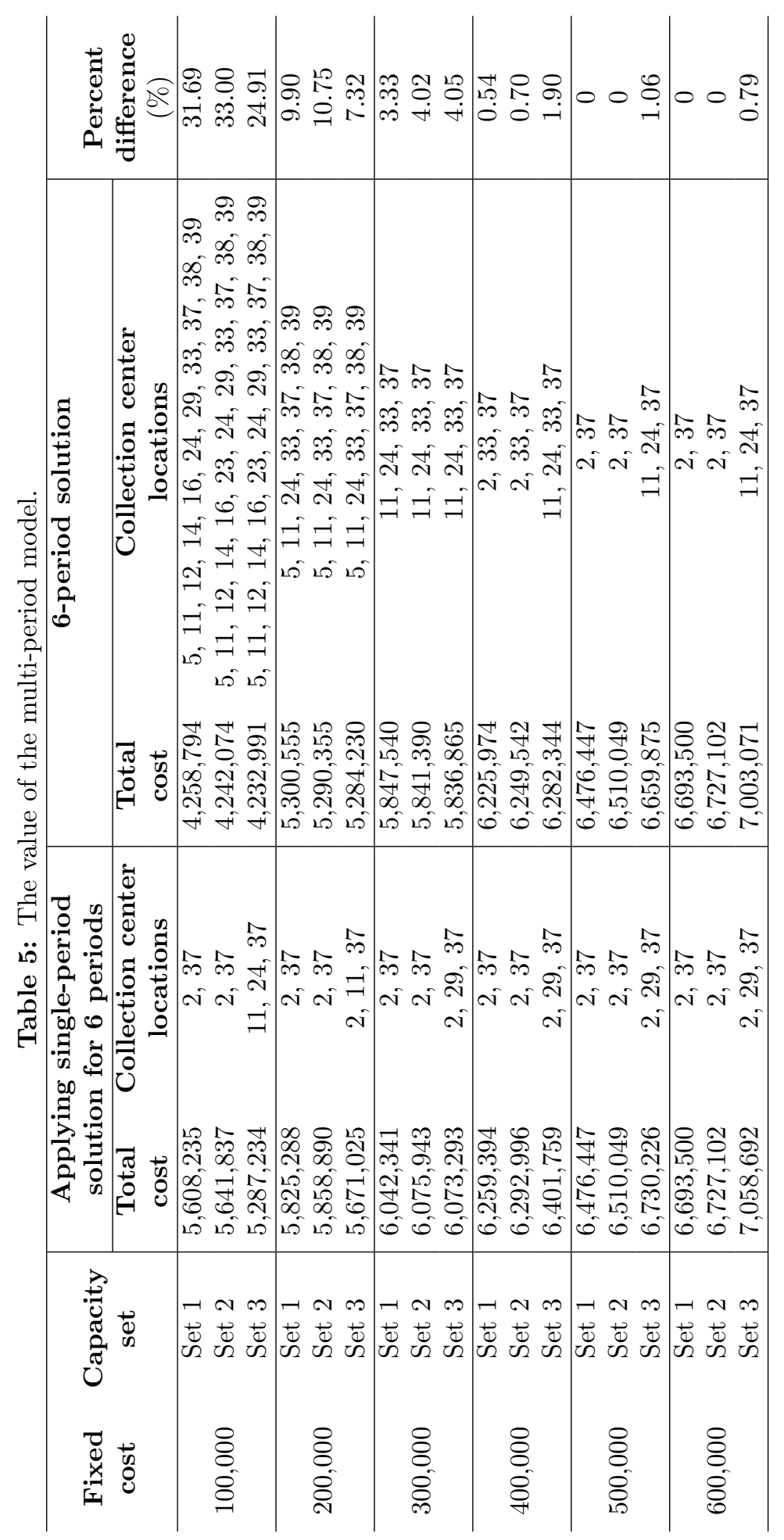


$0.79 \%$, two of the collection centers among three are located at different nodes under the static and multi-period planning strategies.

This analysis shows that in addition to the possibility of optimizing the flow sent to different firms, the decision maker can also gain in terms of total cost when the planning is done in a multi-period setting.

\subsection{Solution potential of the model}

Lastly, we would like to analyze the solution potential of our proposed model by using the commercial solver CPLEX. As listed in the previous sections, the problem is solved by using the lexicographic method proposed in Section 5.1 in reasonable CPU times. The highest CPU time requirement among all the instances listed above is less than a minute which is very reasonable for a strategic problem.

First, we increased the number of periods in the planning horizon to 36 periods by using the base case parameters. With 36 periods, the problem is solved in around 5 minutes with CPLEX version 12.4 .

Next, we changed the number of generation points and the potential collection center locations from 39 to 105 by including the municipalities and districts within the neighboring cities of Ankara in the Central Anatolian Region. With 105 candidate locations and 6-periods, using the base case parameters, the problem is solved in less than 6 minutes by using CPLEX.

This preliminary analysis on the total number of periods and potential collection center locations showed that our model can be solved in reasonable times by using commercially available solvers.

\section{Conclusions}

In this paper, we proposed a new modeling framework for collection center location problem in reverse logistics networks. The problem is motivated by the collection center location problem faced by the municipalities within the European Union WEEE Directive (2002). The proposed model for this location problem also considers objectives related to equity. The problem is modeled as a multi-objective mixed integer programming formulation with three objectives. The first objective is to minimize total cost, the second is to ensure equity among different firms, and the third is to provide a steady flow of products to each firm.

The problem is modeled within a multi-period setting. The model decides on the locations and the capacities of the collection centers, the amounts of products to send from generation points to collection centers, and the amounts of products to send from collection centers to firms through a discrete and finite planning horizon.

An implementation of the model is presented with data from Turkey within the context of 
WEEE collection. For this application, the lexicographic method is adopted for the solution of the multi-objective model. Solutions are analyzed with emphasis on the resulting reverse logistics networks and the equity objectives. Extensive sensitivity and scenario analysis are presented. The model is solved in reasonable CPU times by a commercial solver for instances with realistic sizes.

The results showed that more collection centers needed to be established to reduce transportation costs when the fixed cost values were lower. The locations of the collection centers were not affected by the changes in the growth rate of the collected products. In our experimentation, no matter what the value of the amounts of generated products were, there was always a solution where each firm can get the same excess amount of products from the collection centers. Under different growth rate scenarios, it was again possible to send the same excess amount of products to different firms through the planning horizon. It was more difficult to send a steady flow of products to firms through the planning horizon when there was an exponential increase in the growth rate of the products.

The results through the trade-off analysis showed that optimum Equity $y_{1}$ value can be achieved with a relatively little increase in total costs, whereas, it may not be cost-effective to

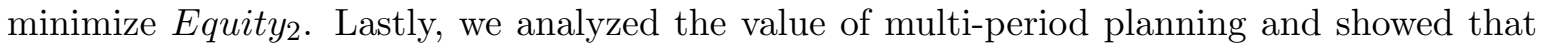
using a multi-period approach can be advantageous in terms of total cost compared to using a static approach in solving this collection center location problem.

The third objective of the problem aims to ensure a steady flow of products to each firm during the planning horizon. It is assumed that a steady flow is preferred for remanufacturing activities. However, instead of a steady flow in relatively low amounts, some firms may prefer a bulk flow in order to take advantage from the economies of scale. In such a case, it is possible to modify the third objective function separately for each firm, for example to maximize the amount of consolidated flow.

Another possible future research direction is to consider uncertainty in the amounts of products generated from the generation points. In this study, we analyzed different instances for the changes in the amount of supply and different scenarios for the growth rate of the products. Our results showed that the locations of the collection centers are not affected much from these changes.

\section{References}

Akçalı, E., Çetinkaya, S., Üster, H., 2009. Network design for reverse and closed-loop supply chains: An annoted bibliography of models and solution approaches. Networks 53, 231-248.

Aksen, D., Aras, N., Karaarslan, G., 2009. Design and analysis of government subsidized 
collection systems for incentive-dependent returns. International Journal of Production Economics 119, 308-327.

Alçada-Almeida, L., Coutinho-Rodrigues, J., Current, J., 2009. A multiobjective modeling approach to locating incinerators. Socio-Economic Planning Sciences 43, 111-120.

Alumur, S. A., Nickel, S., Saldanha-da-Gama, F., Verter, V., 2012. Multi-period reverse logistics network design. European Journal of Operational Research 220, 67-78.

Aras, N., Aksen, D., 2008. Locating collection centers for distance- and incentive-dependent returns. International Journal of Production Economics 111, 316-333.

Aras, N., Aksen, D., Tanugur, A. G., 2008. Locating collection centers for incentive-dependent returns under a pick-up policy with capacitated vehicles. European Journal of Operational Research 191, 1223-1240.

Aras, N., Boyacı, T., Verter, V., 2010. Designing the reverse logistics network. In: Ferguson, M., Souza, G. (Eds.), Closed Loop Supply Chains: New Developments to Improve the Sustainability of Business Practices. CRC Press, pp. 67-98.

Barros, A. I., Dekker, R., Scholten, V., 1998. A two-level network for recycling sand: A case study. European Journal of Operational Research 110, 199-214.

Batta, R., Lejeune, M., Prasad, S., 2014. Public facility location using dispersion, population, and equity criteria. European Journal of Operational Research 234, 819-829.

Bautista, J., Pereira, J., 2006. Modeling the problem of locating collection areas for urban waste management. An application to the metropolotan area of Barcelona. Omega 34, $617-629$.

Berman, O., Drezner, Z., Tamir, A., Wesolowsky, G. O., 2009. Optimal location with equitable loads. Annals of Operations Research 167, 307-325.

Data, 2014. Application data can be downloaded from the address: https://drive.google. com/file/d/OB-YGmXNO5SMOUHZEd2ZOVGtiZjQ/edit?usp=sharing.

De Rosa, V., Gebhard, M., Hartmann, E., Wollenweber, J., 2013. Robust sustainable bidirectional logistics network design under uncertainty. International Journal of Production Economics 145, 184-198.

Dowlatshahi, S., 2000. Developing a theory of reverse logistics. Interfaces 30, 143-155. 
Drezner, T., Drezner, Z., 2011. A note on equity across groups in facility location. Naval Research Logistics 58, 705-711.

Easwaran, G., Üster, H., 2009. Tabu search and benders decomposition approaches for a capacitated closed-loop supply chain network design problem. Transportation Science 43, 301-320.

England and Wales High Court, 2009. Case no: CO/1934/2009 Available at: http://www . bailii.org/ew/cases/EWHC/Admin/2009/2015.html.

European Statistics Institute, 2012. Web site: http://epp.eurostat.ec.europa.eu/ portal/page/portal/eurostat/home/.

European Union WEEE Directive, 2002. Available at http://ec.europa.eu/environment/ waste/weee/legis_en.htm.

Figueiredo, J., Mayerle, S. F., 2008. Designing minimum-cost recycling collection networks with required throughput. Transportation Research Part E 44, 731-752.

Fleischmann, M., Bloemhof-Ruwaard, J. M., Beullens, P., Dekker, R., 2004. Reverse logistics network design. In: Dekker, R., Fleischmann, M., Inderfurth, K., Van Wassenhove, L. N. (Eds.), Reverse logistics: Quantitative models for closed-loop supply chains. SpringerVerlag.

Fleischmann, M., Bloemhof-Ruwaard, J. M., Dekker, R., van der Laan, E., van Nunen, J. A. E. E., Van Wassenhove, L. N., 1997. Quantitative models for reverse logistics: A review. European Journal of Operational Research 103, 1-17.

Fonseca, M., García-Sánchez, A., Ortega-Mier, M., Saldanha-da-Gama, F., 2010. A stochastic bi-objective location model for strategic reverse logistics. TOP 18, 158-184.

Gomes, M. I., Barbosa-Póvoa, A. P., Novais, A. Q., 2011. Modelling a recovery network for WEEE: A case study in Portugal. Waste Management 31, 1645-1660.

Govindan, K., Soleimani, H., Kannan, D., 2015. Reverse logistics and closed-loop supply chain: A comprehensive review to explore the future. European Journal of Operational Research 240, 603-626.

Jayaraman, V., Patterson, R. A., Rolland, E., 2003. The design of reverse distribution networks: Models and solution procedures. European Journal of Operational Research 150, 128-149. 
Kim, J.-S., Lee, D.-H., 2013. A restricted dynamic model for refuse collection network design in reverse logistics. Computers \& Industrial Engineering 66, 1131-1137.

Ko, H., Evans, G. W., 2007. A genetic algorithm-based heuristic for the dynamic integrated forward/reverse logistics network for 3PLs. Computers \& Operations Research 34, 346-366.

Krikke, H., Bloemhof-Ruward, J., Van Wassenhove, L., 2003. Concurrent product closed-loop supply chain design with an application to refrigerators. International Journal of Production Research 41, 3689-3719.

Krikke, H. R., van Hartenb, A., Schuur, P. C., 1999. Business case Roteb: recovery strategies for monitors. Computers \& Industrial Engineering 36, 739-757.

Lee, D.-H., Dong, M., 2009. Dynamic network design for reverse logistics operations under uncertainty. Transportation Research Part E: Logistics and Transportation Review 45, 6171.

Lejeune, M. A., Prasad, S. Y., 2013. Effectiveness-equity models for facility location problems on tree networks. Networks 62, 243-254.

Liştes, O., Dekker, R., 2005. A stochastic approach to a case study for product recovery network design. European Journal of Operational Research 160, 268-287.

Marsh, M. T., Schilling, D. A., 1994. Equity measurement in facility location analysis: A review and framework. European Journal of Operational Research 74, 1-17.

Melo, M. T., Nickel, S., Saldanha-da-Gama, F., 2006. Dynamic multi-commodity capacitated facility location: a mathematical modeling framework for strategic supply chain planning. Computers \& Operational Research 33, 181-208.

Min, H., Ko, H. J., Ko, C. S., 2006. A genetic algorithm approach to developing the multiechelon reverse logistics network for product returns. Omega 34, 56-69.

Pati, R. K., Vrat, P., Kumar, P., 2008. A goal programming model for paper recycling system. Omega 36, 405-417.

Pishvaee, M. S., Farahani, R. Z., Dullaert, W., 2010. A memetic algorithm for bi-objective integrated forward/reverse logistics network design. Computers \& Operations Research 37, $1100-1112$.

Pokharel, S., Mutha, A., 2009. Perspectives in reverse logistics: A review. Resources, Conservation and Recycling 53, 175-182. 
Qin, Z., Ji, X., 2010. Logistics network design for product recovery in fuzzy environment. European Journal of Operational Research 202, 479-490.

Realff, M. J., Ammons, J. C., Newton, D. J., 2004. Robust reverse production system design for carpet recycling. IIE Transactions $36,767-776$.

Salema, M. I., Barbosa-Póvoa, A. P., Novais, A. Q., 2007. An optimization model for the design of a capacitated multi-product reverse logistics network with uncertainty. European Journal of Operational Research 179, 1063-1077.

Salema, M. I., Barbosa-Póvoa, A. P., Novais, A. Q., 2010. Simultaneous design and planning of supply chains with reverse flows: A generic modelling framework. European Journal of Operational Research 203, 336-349.

Sayman, R. U., Akpulat, O., Cordova-Novion, C., 2012. Regulatory Impact Assessment of EU Waste Electrical and Electronic Equipment (WEEE) Directive. Tech. rep., Regional Environmental Center (REC) Turkey, available at http://www.wee-forum.org/sites/ default/files/documents/2012_weee_in_turkey_ria_final.pdf.

Schultmann, F., Engels, B., Rentz, O., 2003. Closed-loop supply chains for spent batteries. Interfaces $33,57-71$.

Srivastava, S., 2008. Network design for reverse logistics. Omega 36, 535-548.

Toso, E. A. V., Alem, D., 2014. Effective location models for sorting recyclables in public management. European Journal of Operational Research 234, 839-860.

Turkish Ministry of Environment WEEE Directive, 2012. Available at http://www . resmigazete.gov.tr/eskiler/2012/05/20120522-5.htm.

Turkish Statistical Institute, 2011. Web site: http://www.turkstat.gov.tr.

UNU, 2008. Review of directive 2002/96/EC on Waste Electrical and Electronic Equipment (WEEE). Available at http://ec.europa.eu/environment/waste/weee/pdf/final_ rep_unu.pdf.

Üster, H., Easwaran, G., Akçali, E., Çetinkaya, S., 2007. Benders decomposition with alternative multiple cuts for a multi-product closed-loop supply chain network design model. Naval Research Logistics 54, 890-907. 